\title{
Differential Effects of Strong and Regular Statins on the Clinical Outcome of Patients With Chronic Kidney Disease Following Coronary Stent Implantation
}

\section{- The Kumamoto Intervention Conference Study (KICS) Registry -}

Masanobu Ishii, MD; Seiji Hokimoto, MD; Tomonori Akasaka, MD; Kazuteru Fujimoto, MD;

Yuji Miyao, MD; Koichi Kaikita, MD; Shuichi Oshima, MD; Koichi Nakao, MD;

Hideki Shimomura, MD; Ryusuke Tsunoda, MD; Toyoki Hirose, MD; Ichiro Kajiwara, MD; Toshiyuki Matsumura, MD; Natsuki Nakamura, MD; Nobuyasu Yamamoto, MD; Shunichi Koide, MD;

Hideki Oka, MD; Yasuhiro Morikami, MD; Naritsugu Sakaino, MD; Kunihiko Matsui, MD; Hisao Ogawa, MD on behalf of the Kumamoto Intervention Conference Study (KICS) Investigators

Background: The aim of this study was to examine the effects of different statins on the clinical outcomes of Japanese patients with coronary stent implants.

Methods and Results: This study included 5,801 consecutive patients (males, 4,160; age, 69.7 \pm 11.1 years, mean \pm SD) who underwent stent implantation between April 2008 and March 2011. They were treated with a strong statin ( $n=3,042,52 \%$, atorvastatin, pitavastatin, or rosuvastatin), a regular statin ( $n=1,082,19 \%$, pravastatin, simvastatin, or fluvastatin) or no statin ( $n=1,677,29 \%)$. The patients with chronic kidney disease (CKD) were divided into mildto-moderate CKD ( $30 \leq$ eGFR<60, $n=1,956)$ and severe CKD (eGFR <30, n=559). Primary endpoints included cardiovascular death and nonfatal myocardial infarction, including stent thrombosis and ischemic stroke. The clinical outcome for the primary endpoint in mild-to-moderate CKD patients treated with a strong statin (hazard ratio 0.50 , $95 \%$ confidence interval $0.31-0.81 ; P=0.005)$ was significantly lower than in those on no statins, but that in the patients treated with a regular statin was not $(P=0.160)$. The clinical outcome for the primary endpoint in severe CKD patients treated with a strong or regular statin was no different than not being on statin therapy $(P=0.446, P=0.194$, respectively).

Conclusions: In patients with mild-to-moderate CKD, only strong statins were associated with lower risk compared with no statin, but regular statins were not. It is possible that taking a strong statin from the early stage of CKD is useful for suppression of cardiovascular events. (Circ $J$ 2015; 79: 1115-1124)

Key Words: Cardiovascular events; Chronic kidney disease; Statins; Stents

MG-CoA reductase inhibitors (statins) are used to prevent cardiovascular events because they are known to reduce the risk of cardiovascular and cerebrovas- cular events, both directly and indirectly. The reduction in the risk of cardiovascular events is achieved by lowering lowdensity lipoprotein cholesterol (LDL-C) levels. ${ }^{1,2}$ Several stud-

Received July 21, 2014; revised manuscript received December 8, 2014; accepted January 6, 2015; released online February 24, 2015 Time for primary review: 50 days

Department of Cardiovascular Medicine, Graduate School of Medical Sciences, Kumamoto University, Kumamoto (M.I, S.H., T.A., K.K., K.M., H. Ogawa); Division of Cardiology, Kumamoto Central Hospital, Kumamoto (S.O.); Cardiovascular Center, Kumamoto Saiseikai Hospital, Kumamoto (K.N.); National Hospital Organization Kumamoto Medical Center, Kumamoto (K.F., Y.M.); Division of Cardiology, Fukuoka Tokushukai Hospital, Fukuoka (H.S.); Kumamoto Red Cross Hospital, Kumamoto (R.T.); Division of Cardiology, Minamata City Hospital and Medical Center, Minamata (T.H.); Division of Kumamoto City Hospital, Kumamoto (Y.M.); Division of Amakusa Regional Medical Center, Amakusa (N.S.); Division of Arao City Hospital, Arao (I.K.); Division of Kumamoto Rosai Hospital, Yatsushiro (T.M.); Division of Shinbeppu Hospital, Beppu (N.N.); Miyazaki Prefectural Nobeoka Hospital, Nobeoka (N.Y.); Division of Health Insurance Yatsushiro General Hospital, Yatsushiro (S.K.); and Division of Health Insurance Hitoyoshi General Hospital, Hitoyoshi (H. Oka), Japan

Members are listed in the Appendix.

Mailing address: Seiji Hokimoto, MD, Department of Cardiovascular Medicine, Graduate School of Medical Sciences, Kumamoto University, 1-1-1, Honjo, Chuo-ku, Kumamoto 860-8556, Japan. E-mail: shokimot@kumamoto-u.ac.jp

ISSN-1346-9843 doi:10.1253/circj.CJ-14-0789

All rights are reserved to the Japanese Circulation Society. For permissions, please e-mail: cj@j-circ.or.jp 
ies have reported that intensive treatment with lipid-lowering agents provides better protection against coronary artery plaque formation and prevents cardiovascular events compared with moderate treatment. ${ }^{3,4}$ For example, intensive statin treatment appears to improve clinical outcomes after acute coronary syndrome (ACS) and stable ischemic heart disease in Western countries, compared with standard statin treatment. ${ }^{3,5,6}$ In this regard, statins have other effects, in addition to their lipidlowering effects, such as antiinflammatory and antioxidants effects.

\section{Editorial p 976}

The 2013 American College of Cardiology and the American
Heart Association (ACC/AHA) Guidelines on the Assessment of Cardiovascular Risk recommend the use of intensive statin treatment for secondary prevention in high-risk patients with clinical atherosclerotic cardiovascular disease (ASCVD), regardless of the level of LDL-C. ${ }^{7}$ In Japan, statins tend to be used at low doses compared with Western countries, and the lipid management policy in Japan is to lower LDL-C to less than $100 \mathrm{mg} / \mathrm{dl}$ for secondary prevention in patients with ASCVD. ${ }^{8}$ Furthermore, a regular statin or low-dose strong statin is administered in Japan at the start of treatment of dyslipidemia as a strategy to protect against unwanted side effects. The use of strong statins is limited to high-risk patients with coronary artery disease (CAD) after percutaneous coronary intervention (PCI), but the "high" dose of statin used in Japan, even in such

\begin{tabular}{|c|c|c|c|c|}
\hline (A) Clinical characteristics & $\begin{array}{l}\text { Strong statin } \\
(n=3,042)\end{array}$ & $\begin{array}{l}\text { Regular statin } \\
(n=1,082)\end{array}$ & $\begin{array}{l}\text { No statin } \\
(n=1,677)\end{array}$ & $P$ value \\
\hline Male (\%) & $2,190(72.0)$ & $774(71.5)$ & 1,196 (71.3) & 0.877 \\
\hline Age (years) & $67.6 \pm 11.1^{\star, \star \star}$ & $70.9 \pm 10.5^{\star}$ & $72.9 \pm 10.5$ & $<0.001$ \\
\hline Elderly ( $\geq 75$ years) & $901(29.6)$ & $446(41.2)$ & $838(50.0)$ & $<0.001^{\dagger}$ \\
\hline BMI $\left(\mathrm{kg} / \mathrm{m}^{2}\right)$ & $24.4 \pm 3.4^{\star, \star \star}$ & $23.7 \pm 3.4^{\star}$ & $23.1 \pm 3.4$ & $<0.001$ \\
\hline Obesity (BMI $\geq 25)$ & $1,203(39.7)$ & $351(32.5)$ & $426(25.9)$ & $<0.001^{\dagger}$ \\
\hline ACS (\%) & $1,701(55.9)$ & $532(49.2)$ & $818(48.8)$ & $<0.001^{\dagger}$ \\
\hline Left main trunk lesion (\%) & $180(5.9)$ & $63(5.8)$ & $121(7.2)$ & 0.169 \\
\hline Current smoker (\%) & $871(28.6)$ & $245(22.6)$ & $319(19.0)$ & $<0.001^{\dagger}$ \\
\hline Hypertension (\%) & $2,355(77.4)$ & $873(80.7)$ & $1,272(75.8)$ & 0.012 \\
\hline Dyslipidemia (\%) & $2,474(81.3)$ & $735(67.9)$ & $439(26.2)$ & $<0.001^{\dagger}$ \\
\hline Previous MI (\%) & $621(20.4)$ & $254(23.5)$ & $317(18.9)$ & 0.014 \\
\hline Previous stroke (\%) & $398(13.1)$ & $146(13.5)$ & $236(14.1)$ & 0.634 \\
\hline PAD (\%) & $186(6.1)$ & $96(8.9)$ & $164(9.8)$ & $<0.001^{\dagger}$ \\
\hline Diabetes (\%) & $1,356(44.6)$ & $451(41.7)$ & $654(39.0)$ & $0.001^{\dagger}$ \\
\hline eGFR $\left(\mathrm{ml} / \mathrm{min} / 1.73 \mathrm{~m}^{2}\right)$ & $66.3 \pm 25.4^{*}$ & $65.9 \pm 97.7^{*}$ & $54.9 \pm 27.0$ & $<0.001$ \\
\hline CKD $($ eGFR <60) & $1,134(37.3)$ & $473(43.7)$ & $908(54.1)$ & $<0.001^{\dagger}$ \\
\hline $\begin{array}{l}\text { Mild-to-moderate CKD } \\
(30 \leq e G F R<60)\end{array}$ & $970(31.9)$ & $380(35.1)$ & $606(36.1)$ & $0.007^{\dagger}$ \\
\hline Severe CKD (eGFR<30) & $164(5.4)$ & $93(8.6)$ & $302(18.0)$ & $<0.001^{\dagger}$ \\
\hline Hemodialysis (\%) & $62(2.0)$ & $41(3.8)$ & $183(10.9)$ & $<0.001^{\dagger}$ \\
\hline $\mathrm{HbA1c}(\%)$ & $6.2 \pm 1.4^{*, * *}$ & $6.0 \pm 1.1$ & $5.9 \pm 1.2$ & $<0.001$ \\
\hline LDL-C (mg/dl) & $80.5 \pm 22.7$ & $94.7 \pm 27.7$ & Not available & $0.0056+\dagger$ \\
\hline Thienopyridine derivative (\%) & $2,979(97.9)$ & $1,052(97.2)$ & $1,526(91.0)$ & $<0.0011^{\dagger}$ \\
\hline Ticlopidine (\%) & $1,266(41.6)$ & $415(38.4)$ & $573(34.2)$ & $<0.001^{\dagger}$ \\
\hline Clopidogrel (\%) & $1,738(57.1)$ & $649(60.0)$ & $958(57.1)$ & 0.231 \\
\hline$\beta$-blocker (\%) & $1,342(44.1)$ & $431(39.8)$ & $447(26.7)$ & $<0.001^{\dagger}$ \\
\hline ACEI or ARB (\%) & $2,297(75.5)$ & $815(75.3)$ & $972(58.0)$ & $<0.001^{\dagger}$ \\
\hline ACEI (\%) & $1,076(35.4)$ & $355(32.8)$ & $382(22.8)$ & $<0.001^{\dagger}$ \\
\hline ARB (\%) & $1,281(42.1)$ & $481(44.5)$ & $620(37.0)$ & $<0.001^{\dagger}$ \\
\hline CCB (\%) & $1,325(43.6)$ & $513(47.4)$ & $727(43.4)$ & 0.063 \\
\hline \multicolumn{5}{|l|}{ Stent } \\
\hline DES (\%) & $1,840(60.5)$ & $687(63.5)$ & $986(58.8)$ & 0.048 \\
\hline Bare metal stent (\%) & $1,202(39.5)$ & $395(36.5)$ & $691(41.2)$ & 0.048 \\
\hline (B) Clinical outcomes & $\begin{array}{c}\text { Strong statin } \\
(n=3,042)\end{array}$ & $\begin{array}{l}\text { Regular statin } \\
(n=1,082)\end{array}$ & $\begin{array}{l}\text { No statin } \\
(n=1,677)\end{array}$ & $P$ value \\
\hline Primary endpoint (\%) & $69(2.3)$ & $38(3.5)$ & $144(8.6)$ & $<0.001^{\dagger}$ \\
\hline Cardiovascular death (\%) & $28(0.9)$ & $16(1.5)$ & $118(7.0)$ & $<0.001^{\dagger}$ \\
\hline Nonfatal MI (\%) & $29(1.0)$ & $9(0.8)$ & $10(0.6)$ & 0.432 \\
\hline Ischemic stroke (\%) & $12(0.4)$ & $13(1.2)$ & $16(1.0)$ & $0.009^{\dagger}$ \\
\hline
\end{tabular}




\begin{tabular}{|c|c|c|c|c|c|c|c|c|}
\hline \multirow{2}{*}{$\begin{array}{l}\text { (C) Results of univariate and } \\
\text { multivariate cox proportional } \\
\text { hazards analyses }\end{array}$} & \multicolumn{4}{|c|}{ Primary endpoint $(n=251)$} & \multicolumn{4}{|c|}{ Cardiovascular death $(n=162)$} \\
\hline & $\begin{array}{l}\text { Unadjusted } \\
\text { HR (95\% Cl) }\end{array}$ & $P$ value & $\begin{array}{c}\text { Adjusted } \\
\text { HR }(95 \% \mathrm{Cl})\end{array}$ & $P$ value & $\begin{array}{l}\text { Unadjusted } \\
\mathrm{HR}(95 \% \mathrm{Cl})\end{array}$ & $P$ value & $\begin{array}{c}\text { Adjusted } \\
\text { HR }(95 \% \mathrm{Cl})\end{array}$ & $P$ value \\
\hline Strong statin $¥$ & $\begin{array}{c}0.27 \\
(0.20-0.36)\end{array}$ & $<0.001$ & $\begin{array}{c}0.46 \\
(0.33-0.64)\end{array}$ & $<0.001$ & $\begin{array}{c}0.13 \\
(0.08-0.19)\end{array}$ & $<0.001$ & $\begin{array}{c}0.32 \\
(0.20-0.52)\end{array}$ & $<0.001$ \\
\hline Regular statin $\ddagger$ & $\begin{array}{c}0.42 \\
(0.30-0.61)\end{array}$ & $<0.001$ & $\begin{array}{c}0.67 \\
(0.46-0.98)\end{array}$ & 0.041 & $\begin{array}{c}0.20 \\
(0.12-0.34)\end{array}$ & $<0.001$ & $\begin{array}{c}0.48 \\
(0.27-0.82)\end{array}$ & 0.008 \\
\hline Age $\geq 75$ years & $\begin{array}{c}2.36 \\
(1.84-3.04)\end{array}$ & $<0.001$ & $\begin{array}{c}1.54 \\
(1.17-2.04)\end{array}$ & 0.002 & $\begin{array}{c}2.96 \\
(2.15-4.07)\end{array}$ & $<0.001$ & $\begin{array}{c}1.59 \\
(1.11-2.28)\end{array}$ & 0.011 \\
\hline Obesity & $\begin{array}{c}0.67 \\
(0.50-0.89)\end{array}$ & 0.006 & $\begin{array}{c}1.05 \\
(0.78-1.41)\end{array}$ & 0.757 & $\begin{array}{c}0.60 \\
(0.42-0.88)\end{array}$ & 0.008 & $\begin{array}{c}1.07 \\
(0.73-1.58)\end{array}$ & 0.721 \\
\hline Current smoker & $\begin{array}{c}1.06 \\
(0.80-1.41)\end{array}$ & 0.679 & & & $\begin{array}{c}0.87 \\
(0.60-1.26)\end{array}$ & 0.451 & & \\
\hline ACS & $\begin{array}{c}3.55 \\
(2.62-4.81)\end{array}$ & $<0.001$ & $\begin{array}{c}2.73 \\
(1.96-3.80)\end{array}$ & $<0.001$ & $\begin{array}{c}4.50 \\
(2.99-6.76)\end{array}$ & $<0.001$ & $\begin{array}{c}2.66 \\
(1.69-4.17)\end{array}$ & $<0.001$ \\
\hline Previous MI & $\begin{array}{c}0.89 \\
(0.64-1.22)\end{array}$ & 0.449 & & & $\begin{array}{c}0.98 \\
(0.67-1.44)\end{array}$ & 0.935 & & \\
\hline PAD & $\begin{array}{c}1.46 \\
(0.98-2.18)\end{array}$ & 0.062 & $\begin{array}{c}1.45 \\
(0.95-2.22)\end{array}$ & 0.089 & $\begin{array}{c}1.80 \\
(1.14-2.85)\end{array}$ & 0.012 & $\begin{array}{c}1.96 \\
(1.17-3.26)\end{array}$ & 0.010 \\
\hline Hypertension & $\begin{array}{c}0.88 \\
(0.66-1.17)\end{array}$ & 0.363 & & & $\begin{array}{c}0.75 \\
(0.53-1.05)\end{array}$ & 0.095 & $\begin{array}{c}1.07 \\
(0.73-1.55)\end{array}$ & 0.743 \\
\hline Diabetes & $\begin{array}{c}0.90 \\
(0.70-1.16)\end{array}$ & 0.415 & & & $\begin{array}{c}0.76 \\
(0.55-1.04)\end{array}$ & 0.087 & $\begin{array}{c}0.97 \\
(0.69-1.37)\end{array}$ & 0.871 \\
\hline CKD & $\begin{array}{c}2.63 \\
(2.02-3.41)\end{array}$ & $<0.001$ & $\begin{array}{c}1.96 \\
(1.47-2.59)\end{array}$ & $<0.001$ & $\begin{array}{c}3.71 \\
(2.61-5.25)\end{array}$ & $<0.001$ & $\begin{array}{c}2.32 \\
(1.59-3.40)\end{array}$ & $<0.001$ \\
\hline Thienopyridine & $\begin{array}{c}0.08 \\
(0.06-0.11)\end{array}$ & $<0.001$ & $\begin{array}{c}0.15 \\
(0.11-0.21)\end{array}$ & $<0.001$ & $\begin{array}{c}0.04 \\
(0.03-0.06)\end{array}$ & $<0.001$ & $\begin{array}{c}0.12 \\
(0.08-0.17)\end{array}$ & $<0.001$ \\
\hline$\beta$-blocker & $\begin{array}{c}0.63 \\
(0.48-0.83)\end{array}$ & 0.001 & $\begin{array}{c}0.85 \\
(0.63-1.14)\end{array}$ & 0.272 & $\begin{array}{c}0.41 \\
(0.28-0.60)\end{array}$ & $<0.001$ & $\begin{array}{c}0.73 \\
(0.48-1.11)\end{array}$ & 0.148 \\
\hline ACEI or ARB & $\begin{array}{c}0.43 \\
(0.34-0.55)\end{array}$ & $<0.001$ & $\begin{array}{c}0.66 \\
(0.50-0.88)\end{array}$ & 0.005 & $\begin{array}{c}0.24 \\
(0.18-0.33)\end{array}$ & $<0.001$ & $\begin{array}{c}0.53 \\
(0.36-0.78)\end{array}$ & 0.001 \\
\hline CCB & $\begin{array}{c}0.36 \\
(0.26-0.48)\end{array}$ & $<0.001$ & $\begin{array}{c}0.49 \\
(0.36-0.67)\end{array}$ & $<0.001$ & $\begin{array}{c}0.17 \\
(0.11-0.27)\end{array}$ & $<0.001$ & $\begin{array}{c}0.28 \\
(0.17-0.45)\end{array}$ & $<0.001$ \\
\hline DES & $\begin{array}{c}0.39 \\
(0.30-0.51)\end{array}$ & $<0.001$ & $\begin{array}{c}0.71 \\
(0.54-0.94)\end{array}$ & 0.017 & $\begin{array}{c}0.27 \\
(0.20-0.38)\end{array}$ & $<0.001$ & $\begin{array}{c}0.58 \\
(0.40-0.83)\end{array}$ & 0.003 \\
\hline
\end{tabular}

(A) ${ }^{\star} \mathrm{P}<0.05$ vs. No statin, post-hoc multiple comparison by Bonferroni method; ${ }^{*} \mathrm{P}<0.05$ vs. Regular statin, post-hoc multiple comparison by Bonferroni method; ${ }^{\dagger} \mathrm{P}<0.05$, chi-square test for trend was used to assess a linear trend in proportions across the categories; ${ }^{\dagger}$ statistical significance of differences in mean values between the strong and regular statin groups assessed by Student's t-test. (B) ${ }^{\mathrm{t} P}<0.05$, chi-square test for trend was used to assess a liner trend in proportions across the categories. (C) ${ }^{\ddagger} \mathrm{vs}$. No statin.

$\mathrm{ACEl}$, angiotensin-converting enzyme inhibitor; ACS, acute coronary syndrome; ARB, angiotensin-receptor blocker; BMI, body mass index; $\mathrm{CCB}$, calcium-channel blocker; Cl, confidence interval; CKD, chronic kidney disease; DES, drug-eluting stent; eGFR, estimated glomerular filtration rate; HR, hazard ratio; KICS, Kumamoto Intervention Conference Study; LDL-C, low-density lipoprotein cholesterol; MI, myocardial infarction; PAD, peripheral arterial disease.

patients, is lower than that used in Western countries. In this regard, the incidence of cardiovascular events is low in Japan compared with Western countries, and the protective effects of statins on ASCVD have also been reported in Japanese patients. At this stage, however, there is no solid information on whether strong statins are more effective than regular statins in Japan. This report describes the findings of a prospective nationwide study designed to determine the difference in clinical effect between strong statins (atorvastatin, pitavastatin or rosuvastatin) and regular statins (pravastatin, simvastatin or fluvastatin) in patients with CAD after PCI.

\section{Methods}

\section{Study Population}

The Kumamoto Intervention Conference Study (KICS) is a physician-initiated non-company-sponsored multicenter registry of consecutive patients undergoing PCI in 16 centers across Japan. ${ }^{9}$ Between April 2008 and March 2011, 6,219 consecutive procedures were recorded on the PCI list. All consecutive patients who gave written informed consent were enrolled in this study. The exclusion criteria were: no coronary stenting or unsuccessful coronary stenting procedure, which was defined as residual stenosis $\geq 50 \%$ or major complications during hospitalization, including death, myocardial infarction (MI), subacute thrombosis and emergency coronary artery bypass graft surgery. Finally, 5,801 patients with implanted stents were enrolled in this prospective multicenter study with 12-month follow-up. They included 4,124 patients treated with statins and 1,677 without statins. Furthermore, the statin group was divided into strong statins (atorvastatin, pitavastatin or rosuvastatin; $\mathrm{n}=3,042$ ) and regular statins (pravastatin, simvastatin or fluvastatin; $n=1,082$ ). The selection of treatment was left to the discretion of the attending physician at each hospital, and treatment was mostly tailored to reduce LDL-C to $<100 \mathrm{mg} / \mathrm{dl}$ for secondary prevention. ${ }^{8}$ Compliance with treatment was checked regularly throughout the study. The compliance of patients with the medication was confirmed at hospital discharge by the attending physician of each facility.

The study protocol followed the guidelines of the ethics committee of each institution and written informed consent was provided by each patient or the family of the subject. 


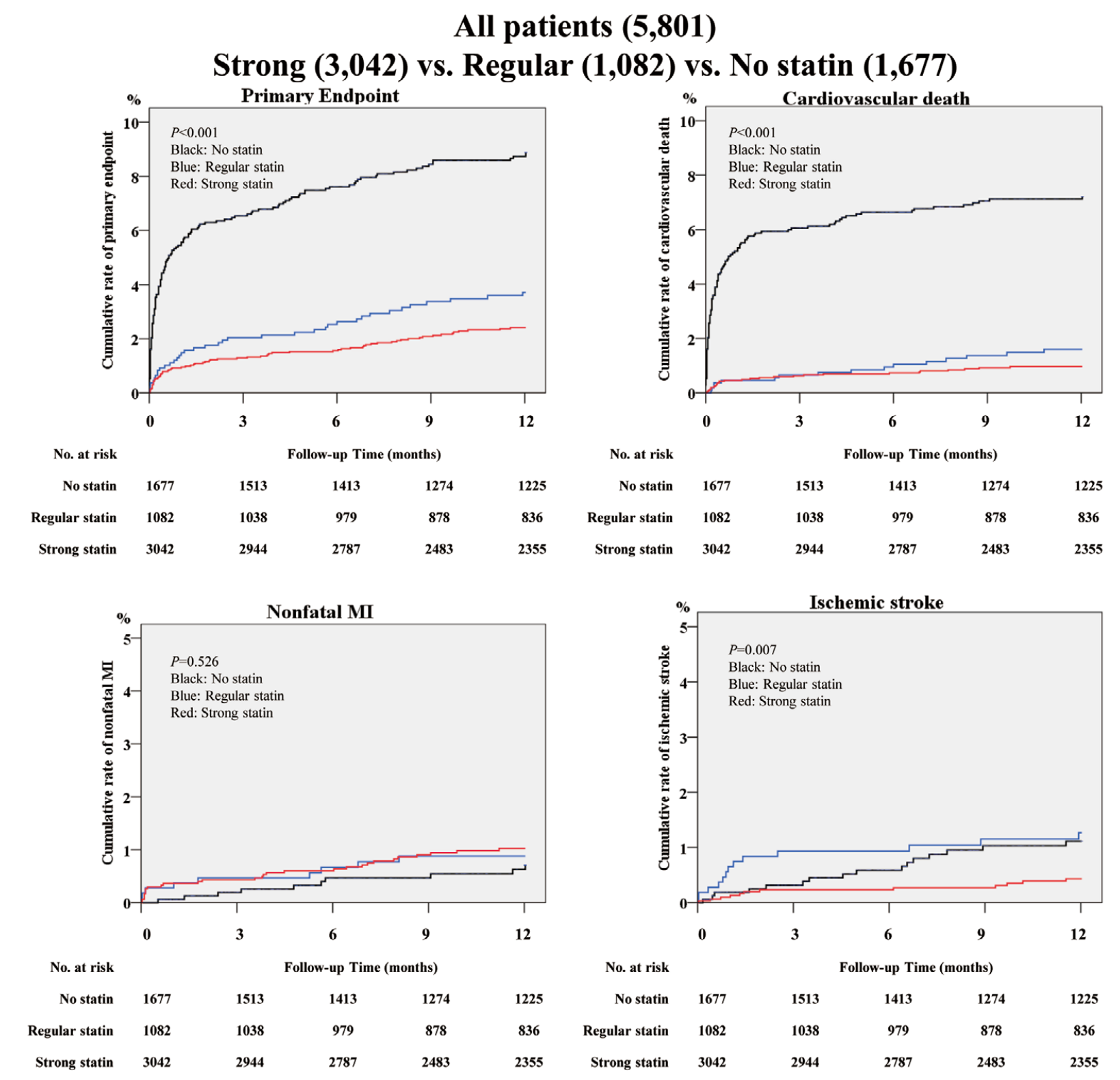

Figure 1. Kaplan-Meier estimates of the cumulative rate of the primary endpoint (cardiovascular death, nonfatal myocardial infarction and ischemic stroke) in strong, regular and no statin groups. There were significant differences in the primary endpoint, cardiovascular death and ischemic stroke among the groups ( $P<0.001, P<0.001, P=0.007$, respectively).

\section{Clinical Outcomes and Definitions}

The primary endpoint was defined as cardiovascular death or nonfatal MI, including stent thrombosis and ischemic stroke. Cardiovascular death was defined as death from MI, stent thrombosis, congestive heart failure, or documented sudden cardiac death. The universal definition of MI was used. ${ }^{10}$ Diagnosis of ischemic stroke was based on clinical and radiological evidence of stroke without intracranial hemorrhage. Chronic kidney disease (CKD) was defined as estimated glomerular filtration rate $(\mathrm{eGFR})<60 \mathrm{ml} / \mathrm{min} / 1.73 \mathrm{~m}^{2}$. For subjects experiencing more than 2 acute events, only the first event was considered in the analysis. The patients were followed up for 12 months or the endpoint.

\section{Statistical Analysis}

Continuous variables are expressed as mean $\pm \mathrm{SD}$, and categorical variables are expressed as frequencies and percentages. Continuous variables were compared among the 3 groups (strong statin, regular statin and no statin) by one-way ANOVA. In the case of $\mathrm{P}<0.05$, post-hoc multiple comparisons were made with the Bonferroni method. For categorical variables, a chisquare test for trend was used to assess a linear trend in proportions across the categories. The data for the level of LDL-C were obtained at 6-9 months after coronary stenting in a single center. The statistical significance of differences in mean values between groups was assessed with Student's t-test. Estimates of the cumulative event rates were calculated by the 
Kaplan-Meier method, and differences among the groups were compared by the log-rank test. Cox proportional hazards regression was used to compute hazard ratios (HRs) and 95\% confidence intervals (CI) as estimates for each endpoint. The HRs were adjusted for clinical characteristics according to the univariate analysis for each event. All variables with $\mathrm{P}<0.10$ in the univariate analysis were considered in the multivariate model. In the Cox proportional hazards regression, we evaluated HRs and 95\% CI of the groups of strong and regular statins, with the no statin group as the reference. $\mathrm{P}<0.05$ denoted the presence of a statistically significant difference. All statistical analyses were performed using SPSS software version 21 (SPSS, Chicago, IL, USA).

\section{Results}

Of the 5,801 patients, 4,124 were on statins (statin group) and 1,677 patients were not treated with statins. The clinical features of these patients are summarized in Table 1A. Patients in the strong statin group were the youngest and had the highest body mass index (BMI), with a higher proportions of ACS, current smokers, dyslipidemia, and diabetes, among the 3 groups. Interestingly, the propensity of patients with CKD was higher in the no statin group among the 3 groups. The mean level of LDL-C measured at 6-9 months after coronary stenting was significantly lower in the strong statin group $(80.5 \pm 22.7 \mathrm{mg} / \mathrm{dl})$ than in the regular statin group $(94.7 \pm 27.7, \mathrm{P}=0.0056)$. As shown in Table 1B, the use of a strong statin was associated with a low frequency of the primary endpoint (cardiovascular death and ischemic stroke) among the groups. The rate of nonfatal MI was not significantly different among the groups. Figure 1 shows the results of Kaplan-Meier analysis and the cumulative rate of clinical outcomes. The rate of the primary endpoint in the strong statin group was the lowest among the groups.

Table 1C shows the results of Cox proportional hazard analysis for the primary endpoint and cardiovascular death. As compared with the no statin group, rate of the primary endpoint was significantly lower in the strong statin group (adjusted $\mathrm{HR}, 0.46$, 95\% CI $0.33-0.64 ; \mathrm{P}<0.001)$ and in the regular statin group (adjusted HR, 0.67, 95\% CI 0.46-0.98; $\mathrm{P}=0.041$ ).

We also performed subgroup analysis of the $\mathrm{CKD}$ patients divided into mild-to-moderate $(30 \leq \mathrm{eGFR}<60)$ and severe CKD $(\mathrm{eGFR}<30)$. Analysis of the mild-to-moderate CKD patients showed no significant differences in the baseline characteristics, except for age, BMI, ACS, hypertension, dyslipidemia, previous MI, diabetes, medication and stent type, among the strong, regular and no statin groups (Table 2A). Also in the severe CKD patients, there were no significant differences in baseline characteristics, except for BMI, ACS, hypertension, dyslipidemia, diabetes and medication. Figure 2 shows the results of Kaplan-Meier analysis and the cumulative rate of the primary endpoint in the mild-to-moderate and severe CKD patients. The primary endpoint of cardiovascular death, nonfatal MI and ischemic stroke in the mild-to-moderate CKD patients occurred in 29 patients $(3.0 \%)$ in the strong statin group, $15(3.9 \%)$ in the regular statin group and $65(10.7 \%)$ in the no statin group (Table 2B). As compared with the no statin group, rate of the primary endpoint was significantly lower in the strong statin group (adjusted HR, 0.50, 95\% CI 0.31-0.81; $\mathrm{P}=0.005$ ), but not in the regular statin group (adjusted HR, $0.65,95 \%$ CI $0.36-1.18 ; \mathrm{P}=0.160$ ) (Table 2C). In the severe CKD patients, the primary endpoint occurred in 9 patients $(5.5 \%)$ in the strong statin group, $4(4.3 \%)$ in the regular statin group and $44(14.6 \%)$ in the no statin group (Table 2B). As compared with the no statin group, the rate of the primary endpoint was not significantly different in the strong statin group (adjusted HR, 0.73, 95\% CI 0.33-1.64; $\mathrm{P}=0.446$ ), and regular statin group (adjusted HR, 0.49, 95\% CI 0.17-1.43; $\mathrm{P}=0.194$ ) (Table 2C). Table 3 showed hazard risks of strong and regular statin use for cardiovascular events in all patients, mild to moderate CKD patients, and severe CKD patients.

\section{Discussion}

The main finding of this study was that both strong and regular statins were associated with a lower rate of the primary endpoint and cardiovascular death compared with no statin therapy. Although there was no difference among the 3 groups for nonfatal MI in all patients, a strong statin was associated with a lower rate of ischemic stroke compared with a regular or no statin. Several studies have shown that lipid-lowering therapy with statins reduces the risk of ischemic stroke, ${ }^{11,12}$ and we consider that the beneficial effect of strong statins on the incidence of ischemic stroke rate is mediated through a reduction of the LDL-C level. Unlike the significant difference in the rate of ischemic stroke, there were no differences in the rate of nonfatal MI among the groups. The reason for this finding is unknown, but we speculate that it is related to the higher incidence of ischemic stroke in Japanese compared with the rate of cardiac events in Western countries, thus showing a larger reduction in stroke incidence.

CKD is an important risk factor for cardiovascular events, similar to dyslipidemia. The risks of cardiovascular mortality and morbidity are increased with progression of CKD. ${ }^{13,14}$ Renal function is considered to be impaired in patients with $\mathrm{CAD}$, and CAD patients with renal dysfunction have poor clinical outcome after revascularization therapy. ${ }^{14-16}$ Furthermore, previous studies reported beneficial effects of statins on the clinical outcome of cardiovascular events in mild-to-moderate CKD patients. ${ }^{17,18}$ The SHARP trial showed that reduction of LDL-C significantly reduced the incidence of cardiovascular events not only in patients with mild-to-moderate but also in those with severe CKD ( $15 \leq \mathrm{eGFR}<30$, not on dialysis). ${ }^{19}$ However, LDL-C lowering therapy in patients with end-stage kidney disease on hemodialysis did not reduce cardiovascular events, similar to the results of 4D and AURORA studies. ${ }^{20,21}$ Meta-analysis demonstrated that statin therapy reduced the risk of cardiovascular events in patients with CKD on hemodialysis; however, progression of CKD resulted in a significant decreased in the effect of statin therapy on cardiovascular events. ${ }^{22}$

Results of our subgroup analysis of severe CKD patients showed that strong and regular statins were not associated with a lower risk for cardiovascular events compared with no statin. A Japanese registry study by Natsuaki et al showed the use of statins was associated with a significantly lower incidence of cardiovascular events in patients who underwent revascularization, especially patients with mild CKD. ${ }^{23}$ In the EVENT registry, study focused on patients undergoing only PCI for CAD and showed favorable outcomes after PCI. ${ }^{24}$ These registry studies failed to prove beneficial effects of statins in patients with severe CKD or on dialysis, as in the present study. Future studies should clarify the effect of statins in patients with severe CKD or on dialysis who undergo coronary stent implantation.

Our other important analysis of the patients with mild-tomoderate CKD showed that the use of a strong statin was associated with a significantly lower rate of cardiovascular events compared with no statin. And there was no significant difference in the rate of cardiovascular events between the use of a regular statin and no statin. Previous studies ${ }^{17-19,23,24} \mathrm{dem}-$ onstrated beneficial effects of statins on clinical outcome of 
Table 2. Clinical Characteristics, Clinical Outcomes and Results of Univariate and Multivariate Cox Proportional Hazards Analyses of Mild-to-Moderate and Severe CKD Patients Included in the KICS Registry

\section{(A) Clinical characteristics}

Male (\%)

Age (years)

Elderly ( $\geq 75$ years)

BMl $\left(\mathrm{kg} / \mathrm{m}^{2}\right)$

Obesity (BMI $\geq 25)$

ACS (\%)

Left main trunk lesion (\%)

Current smoker (\%)

Hypertension (\%)

Dyslipidemia (\%)

Previous MI (\%)

Previous stroke (\%)

PAD (\%)

Diabetes (\%)

HbA1c (\%)

Thienopyridine derivative

Ticlopidine (\%)

Clopidogrel (\%)

$\beta$-blocker (\%)

ACEI or ARB (\%)

ACEI (\%)

ARB (\%)

CCB (\%)

Stent

DES (\%)

Bare metal stent (\%)

\section{(B) Clinical outcomes}

Primary endpoint (\%)

Cardiovascular death (\%)

Nonfatal MI (\%)

Ischemic stroke (\%)
Mild-to-moderate CKD

\begin{tabular}{|c|c|c|c|}
\hline $\begin{array}{l}\text { Strong statin } \\
(n=970)\end{array}$ & $\begin{array}{l}\text { Regular statin } \\
(\mathrm{n}=\mathbf{3 8 0})\end{array}$ & $\begin{array}{l}\text { No statin } \\
(n=606)\end{array}$ & $P$ value \\
\hline $651(67.1)$ & 265 (69.7) & $411(67.8)$ & 0.650 \\
\hline $72.7 \pm 9.3^{\star, \star \star}$ & $74.7 \pm 8.5^{\star}$ & $76.8 \pm 8.6$ & $<0.001$ \\
\hline $453(46.7)$ & $206(54.2)$ & 396 (65.3) & $<0.001^{\dagger}$ \\
\hline $24.3 \pm 3.5^{\star, \star \star}$ & $23.7 \pm 3.4^{\star}$ & $23.1 \pm 3.2$ & $<0.001$ \\
\hline 363 (37.4) & $117(30.8)$ & 139 (22.9) & $<0.0011^{\dagger}$ \\
\hline $505(52.1)$ & $172(45.3)$ & $319(52.6)$ & 0.048 \\
\hline $63(6.5)$ & $30(7.9)$ & $60(9.9)$ & $0.050^{+}$ \\
\hline $182(18.8)$ & $66(17.4)$ & 92 (15.2) & 0.189 \\
\hline $820(84.5)$ & 322 (84.7) & $470(77.6)$ & $0.001^{\dagger}$ \\
\hline $793(81.8)$ & 259 (68.2) & $171(28.2)$ & $<0.001^{\dagger}$ \\
\hline $238(24.5)$ & $109(28.7)$ & $125(20.6)$ & 0.015 \\
\hline $172(17.7)$ & $55(14.5)$ & $100(16.5)$ & 0.348 \\
\hline $80(8.2)$ & $40(10.5)$ & $59(9.7)$ & 0.356 \\
\hline $438(45.2)$ & $163(42.9)$ & 202 (33.3) & $<0.0011^{\dagger}$ \\
\hline $6.2 \pm 1.2^{*}$ & $6.0 \pm 1.1$ & $5.8 \pm 1.1$ & $<0.001$ \\
\hline 950 (97.9) & 367 (96.6) & $542(89.4)$ & $<0.001^{\dagger}$ \\
\hline 439 (45.3) & $140(36.8)$ & 207 (34.2) & $<0.0011^{\dagger}$ \\
\hline $518(53.4)$ & $233(61.3)$ & $335(55.3)$ & 0.031 \\
\hline $431(44.4)$ & 139 (36.6) & $159(26.2)$ & $<0.001^{\dagger}$ \\
\hline $776(80.0)$ & $308(81.1)$ & $362(59.7)$ & $<0.0011^{\dagger}$ \\
\hline 330 (34.0) & $121(31.8)$ & $148(24.4)$ & $<0.0011^{\dagger}$ \\
\hline $470(48.5)$ & $191(50.3)$ & 226 (37.3) & $<0.001^{\dagger}$ \\
\hline $467(48.1)$ & $199(52.4)$ & $249(41.1)$ & $0.001^{\dagger}$ \\
\hline 607 (62.6) & $256(67.4)$ & $348(57.4)$ & 0.006 \\
\hline 363 (37.4) & 124 (32.6) & $258(42.6)$ & 0.006 \\
\hline
\end{tabular}

Mild-to-moderate CKD

$\begin{array}{cccc}\begin{array}{c}\text { Strong statin } \\ (\mathbf{n}=970)\end{array} & \begin{array}{c}\text { Regular statin } \\ (\mathbf{n}=\mathbf{3 8 0})\end{array} & \begin{array}{c}\text { No statin } \\ (\mathbf{n}=606)\end{array} & \text { P value } \\ 29(3.0) & 15(3.9) & 65(10.7) & <0.001^{\dagger} \\ 13(1.3) & 8(2.1) & 55(9.1) & <0.001^{\dagger} \\ 11(1.1) & 1(0.3) & 1(0.2) & 0.040^{\dagger} \\ 5(0.5) & 6(1.6) & 9(1.5) & 0.086^{\dagger}\end{array}$

Mild-to-moderate CKD

(C) Results of univariate and multivariate cox proportional hazards analyses

Strong statin $¥$

Regular statin $¥$

Age $\geq 75$ years

Obesity

ACS

LMT lesion

Hypertension

Diabetes

Thienopyridine

$\beta$-blocker

ACEI or ARB

CCB

DES
Primary endpoint $(n=109)$

\begin{tabular}{rcc} 
P value & $\begin{array}{c}\text { Adjusted HR } \\
\mathbf{( 9 5 \%} \mathbf{~ C l )}\end{array}$ & P value \\
$<0.001$ & $0.50(0.31-0.81)$ & 0.005 \\
$<0.001$ & $0.65(0.36-1.18)$ & 0.160 \\
0.001 & $1.63(1.08-2.47)$ & 0.020 \\
0.185 & & \\
$<0.001$ & $3.13(1.84-5.33)$ & $<0.001$ \\
$<0.001$ & $1.48(0.87-2.51)$ & 0.150 \\
0.068 & $1.06(0.67-1.66)$ & 0.812 \\
0.250 & & \\
$<0.001$ & $0.13(0.08-0.20)$ & $<0.001$ \\
0.002 & $0.68(0.42-1.10)$ & 0.119 \\
$<0.001$ & $0.89(0.57-1.40)$ & 0.616 \\
$<0.001$ & $0.54(0.34-0.85)$ & 0.008 \\
$<0.001$ & $0.73(0.49-1.11)$ & 0.143 \\
\hline
\end{tabular}

(Table 2 continued the next page.) 
(A) Clinical characteristics

Male (\%)

Age (years)

Elderly ( $\geq 75$ years)

BMI $\left(\mathrm{kg} / \mathrm{m}^{2}\right)$

Obesity (BMI $\geq 25$ )

ACS (\%)

Left main trunk lesion (\%)

Current smoker (\%)

Hypertension (\%)

Dyslipidemia (\%)

Previous MI (\%)

Previous stroke (\%)

PAD (\%)

Diabetes (\%)

HbA1c (\%)

Thienopyridine derivative

Ticlopidine (\%)

Clopidogrel (\%)

$\beta$-blocker (\%)

ACEI or ARB (\%)

ACEI (\%)

ARB (\%)

CCB (\%)

Stent

DES (\%)

Bare metal stent (\%)

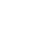

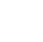




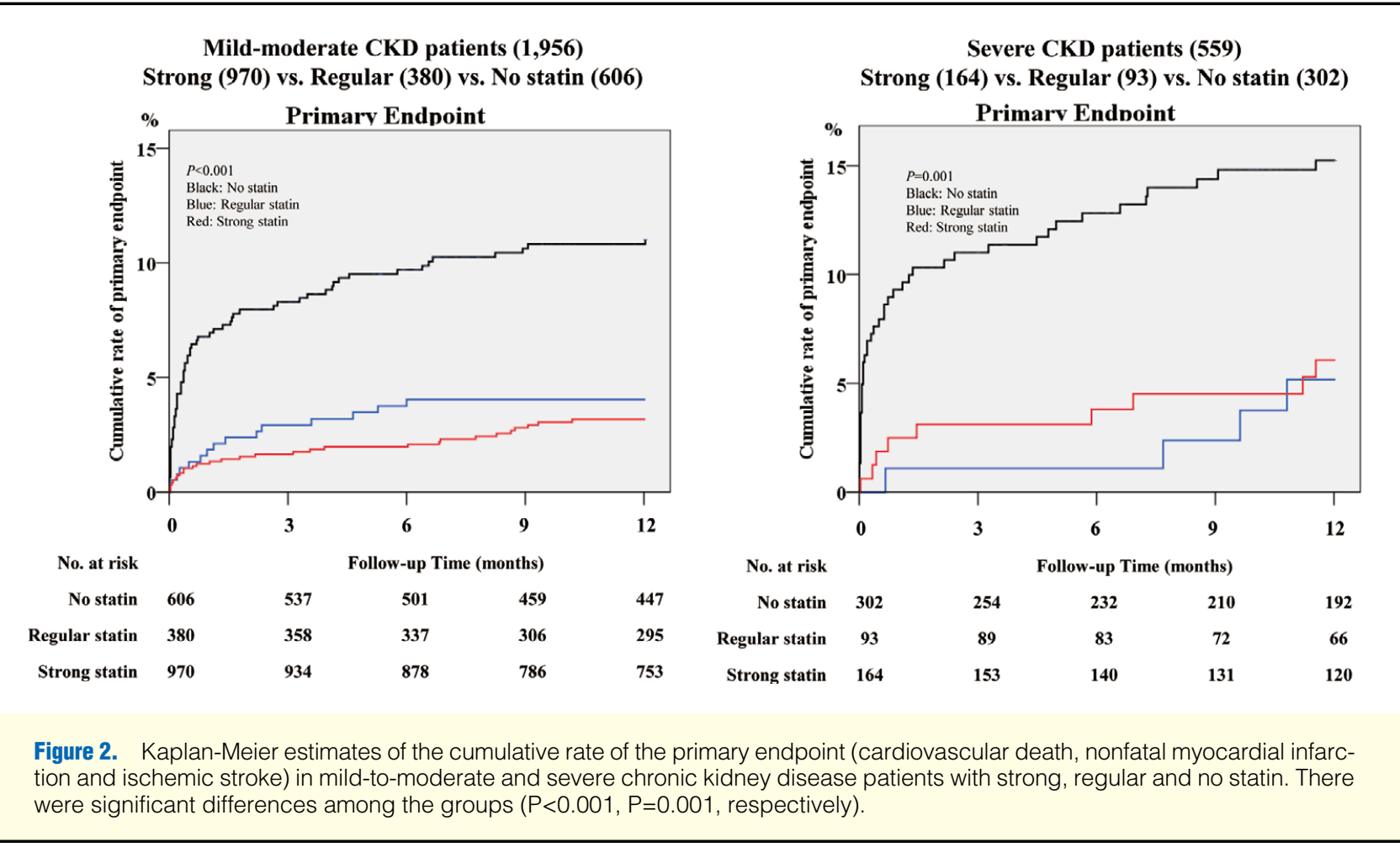

cardiovascular events in mild-to-moderate CKD patients, but, to our knowledge, this study is the first to evaluate the effect of statins on cardiovascular events in CKD patients who underwent coronary stent implantation, by comparing the statin group separately. The other study from the CREDO-Kyoto Registry Cohort- 2 by Natsuaki et al showed that the use of strong statins was associated with a significantly lower incidence of cardiovascular events in patients who underwent revascularization compared with those on a regular statin, ${ }^{25}$ but they did not investigate the effect of strong and regular statins in CKD patients, so it is unclear whether was a difference between strong and regular statins in CKD patients. The present study demonstrated a beneficial effect only of strong statins in mild-tomoderate CKD patients, but not regular statins, suggesting that the effect of statins on cardiovascular events is CKD stagedependent, and that the earlier the CKD stage, the better the effects of a strong statin on cardiovascular events.

These findings probably relate to the plaque characteristics in patients with CKD. Compared with non-CKD patients, coronary plaques in $\mathrm{CKD}$ patients have a large lipid volume, calcification, cholesterol crystals, and plaque disruption. ${ }^{26}$ Kono et al reported that advancement of CKD is associated with a gradual increase in the volumes of necrotic core and dense calcium, a gradual decrease in the necrotic core/dense calcium ratio in coronary plaque, and gradual calcification of the plaque. ${ }^{27}$

We speculate that statins are not efficacious in patients with severe CKD and on hemodialysis because at that stage of the disease process, atherosclerosis of the coronary artery and of the entire body is at an advanced stage. Future studies should clarify the difference between the effects of strong and regular statins in patients with mild-to-moderate CKD.

\section{Study Limitations}

First, our data were registered prospectively, but this study was a post-hoc analysis. Our major problem was the presence of unmeasured confounding factors that affect the risk for cardiovascular events, such as blood pressure and lipid profile (high-density lipoprotein cholesterol, ${ }^{28}$ remnant lipoprotein, ${ }^{29}$ etc). Second, because the absolute number of events of interest was low in this study, the precision of the estimate of effect on the statin group might have been limited, especially in the group with CKD. Third, because we did not check for side effects, the strong statins might not have been tolerated by some patients with regular statin and no statin. So confounding by indication might have occurred in this study. Fourth, we had low power and small sample size to evaluate patients with severe CKD and on dialysis compared with patients with mild-to-moderate CKD. Fifth, we were able to investigate the levels of LDL-C at 6-9 months after coronary stenting in a single center, but we did not obtain the data in all centers. So referral filter bias was considered in this study. Sixth, compliance was only assessed at hospital discharge, so we did not consider the patients whose medication was changed. Finally, we did not collect information on the dose of the statin, and could not confirm dosedependent effects of statins. Because the dose of statin in Japan is different from that used in Western countries, we should design a randomized controlled study to investigate whether intensive statin therapy is useful and safety in Japanese patients, especially CKD patients.

\section{Conclusions}

The present study demonstrated that strong and regular statins were associated with a lower risk for cardiovascular events in patients with CAD who underwent PCI compared with those on no statin therapy. In patients with mild-to-moderate CKD, 
Table 3. Unadjusted and Adjusted Risks of Strong and Regular Statin Use for Primary Endpoint (Composite of Cardiovascular Death, Nonfatal MI, and Ischemic Stoke) in All Patients, Mild-to-Moderate CKD and Severe CKD Patients in the KICS Registry

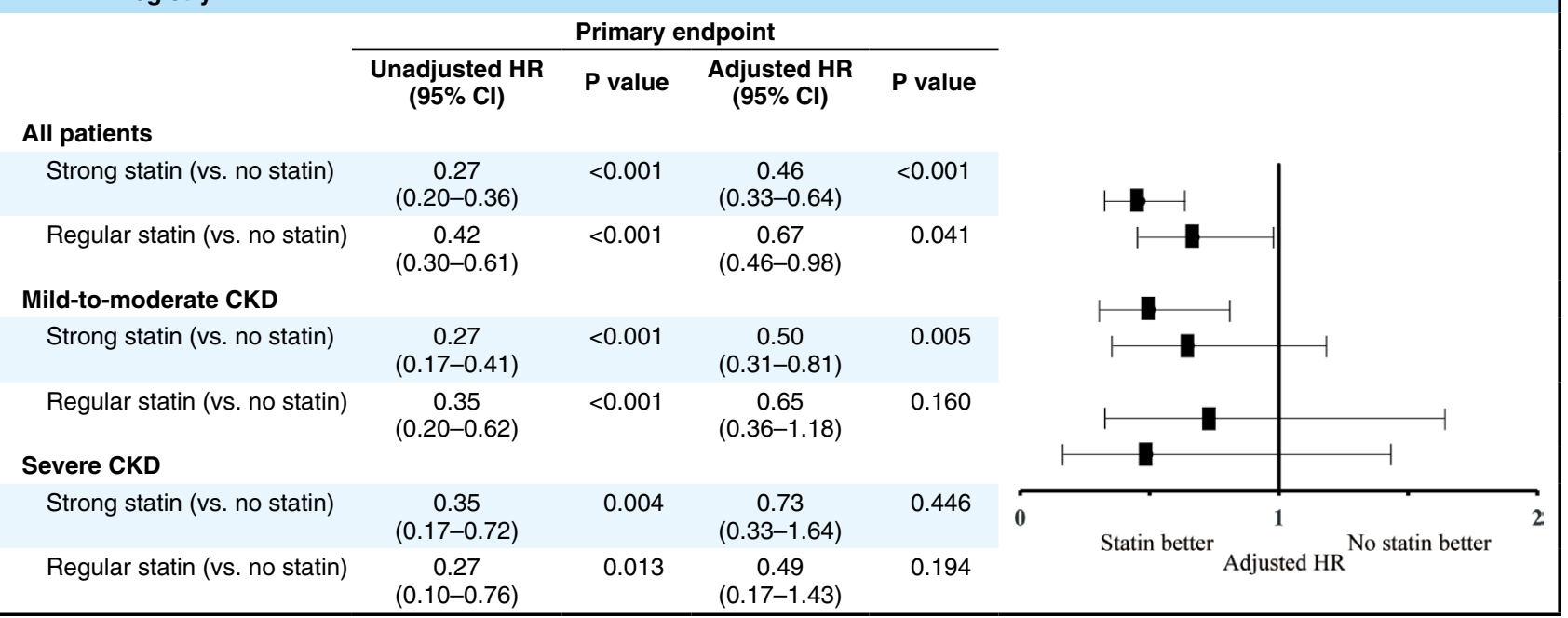

Abbreviations as in Table 1.

only a strong stain was associated with lower risk compared with no statin, but regular statin therapy was not. In Japanese patients with severe CKD, the statins were not associated with lower risk. It is possible that taking a strong statin from the early stage of CKD is useful for suppression of cardiovascular events.

\section{Acknowledgments}

We thank the Medical Secretaries, Naoko Takahashi (Saiseikai Kumamoto Hospital), Yuko Tomita (Fukuoka Tokushukai Hospital), Kayoko Okazaki (Kumamoto Central Hospital), Yuri Iwasaki (Hitoyoshi General Hospital), and Mutsumi Tanaka (Miyazaki Prefectural Nobeoka Hospital). We also thank Aya Miyazaki, Hiroko Koga, Yurie Maeda, Chihiro Yamamoto, Akiyo Kikuchi and Kyoko Watanabe (Kumamoto University) for collecting the data.

\section{Funding Sources}

This study was supported in part by grants-in-aid for scientific research from the Ministry of Education, Culture, Sports, Science and Technology, Japan, the Japan Heart Foundation, Tokyo, and the Japan Vascular Disease Research Foundation, Kyoto, Japan.

\section{Disclosures}

None.

\section{References}

1. Baigent C, Keech A, Kearney PM, Blackwell L, Buck G, Pollicino $\mathrm{C}$, et al. Efficacy and safety of cholesterol-lowering treatment: Prospective meta-analysis of data from 90,056 participants in 14 randomised trials of statins. Lancet 2005; 366: 1267-1278.

2. Sipahi I, Nicholls SJ, Tuzcu EM, Nissen SE. Coronary atherosclerosis can regress with very intensive statin therapy. Cleve Clin J Med 2006; 73: 937-944.

3. Cannon CP, Braunwald E, McCabe CH, Rader DJ, Rouleau JL, Belder R, et al. Intensive versus moderate lipid lowering with statins after acute coronary syndromes. N Engl J Med 2004; 350: 1495-1504.

4. Nissen SE, Tuzcu EM, Schoenhagen P, Brown BG, Ganz P, Vogel $\mathrm{RA}$, et al. Effect of intensive compared with moderate lipid-lowering therapy on progression of coronary atherosclerosis: A randomized controlled trial. JAMA 2004; 291: 1071-1080.

5. Murphy SA, Cannon CP, Wiviott SD, de Lemos JA, Blazing MA, McCabe $\mathrm{CH}$, et al. Effect of intensive lipid-lowering therapy on mortality after acute coronary syndrome (a patient-level analysis of the Aggrastat to Zocor and Pravastatin or Atorvastatin Evaluation and Infection Therapy-Thrombolysis in Myocardial Infarction 22 trials).
Am J Cardiol 2007; 100: 1047-1051.

6. LaRosa JC, Grundy SM, Waters DD, Shear C, Barter P, Fruchart JC, et al. Intensive lipid lowering with atorvastatin in patients with stable coronary disease. $N$ Engl J Med 2005; 352: 1425-1435.

7. Stone NJ, Robinson J, Lichtenstein AH, Bairey Merz CN, LloydJones DM, Blum CB, et al. 2013 ACC/AHA Guideline on the Treatment of Blood Cholesterol to Reduce Atherosclerotic Cardiovascular Risk in Adults: A report of the American College of Cardiology/ American Heart Association Task Force on Practice Guidelines. $J$ Am Coll Cardiol 2014; 63: 2889-2934.

8. Teramoto T, Sasaki J, Ishibashi S, Birou S, Daida H, Dohi S, et al. Comprehensive risk management for the prevention of cardiovascular disease: Executive summary of the Japan Atherosclerosis Society (JAS) guidelines for the diagnosis and prevention of atherosclerotic cardiovascular diseases in Japan - 2012. J Atheroscler Thromb 2013; 20: $603-615$.

9. Chitose T, Hokimoto S, Oshima S, Nakao K, Fujimoto K, Miyao Y, et al. Clinical outcomes following coronary stenting in Japanese patients treated with and without proton pump inhibitor. Circ J 2012; 76: $71-78$.

10. Thygesen K, Alpert JS, White HD, Jaffe AS, Apple FS, Galvani M, et al. Universal definition of myocardial infarction. Circulation 2007; 116: $2634-2653$.

11. Sever PS, Dahlof B, Poulter NR, Wedel H, Beevers G, Caulfield M, et al. Prevention of coronary and stroke events with atorvastatin in hypertensive patients who have average or lower-than-average cholesterol concentrations, in the Anglo-Scandinavian Cardiac Outcomes Trial-Lipid Lowering Arm (ASCOT-LLA): A multicentre randomised controlled trial. Lancet 2003; 361: 1149-1158.

12. Nakamura H, Arakawa K, Itakura H, Kitabatake A, Goto Y, Toyota $\mathrm{T}$, et al. Primary prevention of cardiovascular disease with pravastatin in Japan (MEGA Study): A prospective randomised controlled trial. Lancet 2006; 368: 1155-1163.

13. Levey AS, Coresh J, Balk E, Kausz AT, Levin A, Steffes MW, et al. National Kidney Foundation practice guidelines for chronic kidney disease: Evaluation, classification, and stratification. Ann Intern Med 2003; 139: 137-147.

14. Sarnak MJ, Levey AS, Schoolwerth AC, Coresh J, Culleton B, Hamm LL, et al. Kidney disease as a risk factor for development of cardiovascular disease: A statement from the American Heart Association Councils on Kidney in Cardiovascular Disease, High Blood Pressure Research, Clinical Cardiology, and Epidemiology and Prevention. Circulation 2003; 108: 2154-2169.

15. Reinecke H, Trey T, Matzkies F, Fobker M, Breithardt G, Schaefer RM. Grade of chronic renal failure, and acute and long-term outcome after percutaneous coronary interventions. Kidney Int 2003; 63: 696701.

16. Dan K, Miyoshi T, Ueeda M, Ohtsuka H, Ugawa S, Ohnishi N, et al. Impact of chronic kidney disease on left main coronary artery disease 
and prognosis in Japanese patients. Circ J 2012; 76: 2266-2272.

17. Shepherd J, Kastelein JJ, Bittner V, Deedwania P, Breazna A, Dobson $\mathrm{S}$, et al. Intensive lipid lowering with atorvastatin in patients with coronary heart disease and chronic kidney disease: The TNT (Treating to New Targets) study. J Am Coll Cardiol 2008; 51: 1448-1454.

18. Ridker PM, MacFadyen J, Cressman M, Glynn RJ. Efficacy of rosuvastatin among men and women with moderate chronic kidney disease and elevated high-sensitivity C-reactive protein: A secondary analysis from the JUPITER (Justification for the Use of Statins in Prevention-an Intervention Trial Evaluating Rosuvastatin) trial. J Am Coll Cardiol 2010; 55: 1266-1273.

19. Baigent C, Landray MJ, Reith C, Emberson J, Wheeler DC, Tomson $\mathrm{C}$, et al. The effects of lowering LDL cholesterol with simvastatin plus ezetimibe in patients with chronic kidney disease (Study of Heart and Renal Protection): A randomised placebo-controlled trial. Lancet 2011; 377: 2181-2192.

20. Wanner C, Krane V, Marz W, Olschewski M, Mann JF, Ruf G, et al. Atorvastatin in patients with type 2 diabetes mellitus undergoing hemodialysis. N Engl J Med 2005; 353: 238-248.

21. Fellstrom BC, Jardine AG, Schmieder RE, Holdaas H, Bannister K, Beutler J, et al. Rosuvastatin and cardiovascular events in patients undergoing hemodialysis. N Engl J Med 2009; 360: 1395 - 1407.

22. Hou W, Lv J, Perkovic V, Yang L, Zhao N, Jardine MJ, et al. Effect of statin therapy on cardiovascular and renal outcomes in patients with chronic kidney disease: A systematic review and meta-analysis. Eur Heart J 2013; 34: 1807-1817.

23. Natsuaki M, Furukawa Y, Morimoto T, Sakata R, Kimura T, Investigators CR-KPCRC. Renal function and effect of statin therapy on cardiovascular outcomes in patients undergoing coronary revascularization (from the CREDO-Kyoto PCI/CABG Registry Cohort-2) Am J Cardiol 2012; 110: 1568-1577.

24. Dasari TW, Cohen DJ, Kleiman NS, Keyes MJ, Yen CH, Hanna EB, et al. Statin therapy in patients with chronic kidney disease undergoing percutaneous coronary intervention (from the Evaluation of Drug Eluting Stents and Ischemic Events Registry). Am J Cardiol 2014; 113: $621-625$.

25. Natsuaki M, Furukawa Y, Morimoto T, Nakagawa Y, Ono K, Kaburagi $\mathrm{S}$, et al. Intensity of statin therapy, achieved low-density lipoprotein cholesterol levels and cardiovascular outcomes in Japanese patients after coronary revascularization. Circ J 2012; 76: 1369-1379.

26. Kato K, Yonetsu T, Jia H, Abtahian F, Vergallo R, Hu S, et al. Nonculprit coronary plaque characteristics of chronic kidney disease. Circ Cardiovasc Imaging 2013; 6: 448 -456.

27. Kono K, Fujii H, Nakai K, Goto S, Shite J, Hirata K, et al. Composition and plaque patterns of coronary culprit lesions and clinical characteristics of patients with chronic kidney disease. Kidney Int 2012; 82: $344-351$.

28. Annema W, von Eckardstein A. High-density lipoproteins. Circ J 2013; 77: 2432-2448.

29. Nguyen SV, Nakamura T, Kugiyama K. High remnant lipoprotein predicts recurrent cardiovascular events on statin treatment after acute coronary syndrome. Circ J 2014; 78: 2492-2500.

\section{Appendix}

List of the KICS Investigators

Department of Cardiovascular Medicine, Graduate School of Medical Sciences, Kumamoto University, Kumamoto (Masanobu Ishii, Seiji Hokimoto, Tomonori Akasaka, Koichi Kaikita, Kunihiko Matsui, Hisao Ogawa); Division of Cardiology, Kumamoto Central Hospital, Kumamoto (Shuichi Oshima); Cardiovascular Center, Kumamoto Saiseikai Hospital, Kumamoto (Koichi Nakao); National Hospital Organization Kumamoto Medical Center, Kumamoto (Kazuteru Fujimoto, Yuji Miyao); Division of Cardiology, Fukuoka Tokushukai Hospital, Fukuoka (Hideki Shimomura); Kumamoto Red Cross Hospital, Kumamoto (Ryusuke Tsunoda); Division of Cardiology, Minamata City Hospital and Medical Center, Minamata (Toyoki Hirose); Division of Cardiology, Shinbeppu Hospital, Beppu (Natsuki Nakamura); Division of Cardiology, Amakusa Regional Medical Center, Amakusa (Naritsugu Sakaino); Division of Cardiology, Health Insurance Hitoyoshi General Hospital, Hitoyoshi (Hideki Oka); Division of Cardiology, Miyazaki Prefectural Nobeoka Hospital, Nobeoka (Nobuyasu Yamamoto); Division of Cardiology, Kumamoto City Hospital, Kumamoto (Yasuhiro Morikami); Division of Cardiology, Kumamoto Rosai Hospital, Yatsushiro (Toshiyuki Matsumura); Division of Cardiology, Arao City Hospital, Arao (Ichiro Kajiwara); and Division of Cardiology, Health Insurance Yatsushiro General Hospital, Yatsushiro (Shunichi Koide). 